\title{
Ensaio
}

\section{Da ação à construção: uma experiência com smartphone e trabalho cooperativo no ensino de funções afins no Ensino Fundamental}

\section{From action to construction: an experience with smartphone and cooperative work in teaching related functions in Elementary School}

\section{De la acción a la construcción: una experiencia con el smartphone y el trabajo cooperativo en la docencia de funciones afines en la Escuela Primaria}

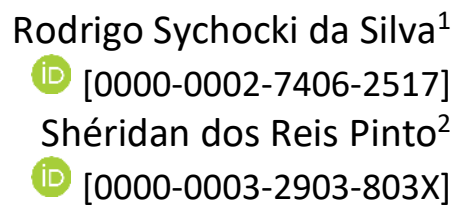

\section{Resumo}

Este texto objetiva apresentar e analisar os resultados de uma sequência de atividades sobre função afim que foi aplicada com um grupo de estudantes do oitavo ano do ensino básico, as quais fazem parte de um recorte dos dados produzidos para uma dissertação em um curso de mestrado em Ensino de Matemática. Este artigo busca analisar quais as contribuições das ações cooperativas na construção de conceitos matemáticos, a partir de uma perspectiva que proporciona e analisa o trabalho coletivo entre os estudantes. O presente artigo, teoricamente, é fundamentado nas ideias sobre cooperação de Jean Piaget e em estudos que refletem sobre o uso de smartphones na Educação Matemática. Caracteriza-se o presente estudo com um viés metodológico qualitativo o qual permitiu, a partir das análises feitas nos diálogos entre os estudantes participantes do experimento, observar a título de conclusão, que uma ação coletiva durante a exploração das situações apresentadas e que envolveu o assunto funções afins, convergiu para uma construção de conhecimentos matemáticos.

Palavras-chave: Aprendizagem matemática. Cooperação. Tecnologia móvel.

\begin{abstract}
This text aims to present and analyze the results of a sequence of activities about functions that was applied with a group of eighth grade students and basic education, such as which parts are part of a cut of the data used for a dissertation in a master's course in Mathematics Teaching. This article seeks to analyze what are the contributions of cooperative actions in the construction of mathematical concepts, from a perspective that provides and analyzes the collective work among students. The present article, theoretically, is based on ideas about Jean Piaget's cooperation and on studies that reflect on the use of smartphones in Mathematics Education. The present study is characterized with a qualitative or qualitative qualitative method, based on the analyzes made in the dialogues between the students participating in the experiment, observing a conclusion title, a collective action during the exploration of the study situations and the involvement of the subject related functions, converged to a construction of mathematical knowledge.
\end{abstract}

Keywords: Mathematics learning. Cooperation. Mobile technology.

\footnotetext{
${ }^{1}$ sychocki.rodrigo@gmail.com, Doutor em Informática na Educação (UFRGS), Docente e orientador permanente no Programa de Pós-Graduação em Ensino de Matemática, Universidade Federal do Rio Grande do Sul, Porto Alegre/Rio Grande do Sul/Brasil.

${ }^{2}$ sherydrp@gmail.com, Mestra em Ensino de Matemática (UFRGS), Professora da rede pública no estado de Santa Catarina, Escola de Educação Básica Ana Machado Dal Toé, Morro Grande/Santa Catarina/Brasil.
} 


\begin{abstract}
Resumen
Este texto tiene como objetivo presentar y analizar los resultados de una secuencia de actividades sobre una función similar que se aplicó con un grupo de estudiantes del octavo año de educación básica, que son parte de un corte de los datos producidos para una disertación en un curso de maestría en Enseñanza de las matemáticas. Este artículo busca analizar las contribuciones de las acciones cooperativas en la construcción de conceptos matemáticos, desde una perspectiva que proporcione y analice el trabajo colectivo entre los estudiantes. El presente artículo, teóricamente, se basa en las ideas de Jean Piaget sobre cooperación y en estudios que reflexionan sobre el uso de teléfonos inteligentes en la educación matemática. El presente estudio se caracteriza por un sesgo metodológico cualitativo que permitió, en base a los análisis realizados en los diálogos entre los estudiantes que participaron en el experimento, observar como conclusión que una acción colectiva durante la exploración de las situaciones presentadas y que involucraba al sujeto, funciones relacionadas, convergentes a una construcción de conocimiento matemático.
\end{abstract}

Palabras claves: Aprendizaje Matemático. Cooperación. Tecnología móvil.

\title{
1 Introdução
}

Segundo Marques (2007) ser professor é ser pesquisador e nessa perspectiva propomos nesse trabalho um olhar sobre uma sequência de atividades que visou a utilização de um aplicativo pelo smartphone e o trabalho coletivo. Nosso objetivo, vinculado à pesquisa de mestrado já realizada, teve o seguinte questionamento: Como o trabalho coletivo aliado ao uso de smartphones estão relacionados com a aprendizagem de funções no oitavo ano? A partir do questionamento que norteou a pesquisa consideramos que o objetivo central da pesquisa de mestrado tenha sido observar, analisar e refletir sobre o trabalho coletivo dos estudantes no estudo de funções ao fazer uso das tecnologias móveis a partir de ações subsidiadas por meio de diálogo entre os pares. Os objetivos secundários foram: planejar e executar uma sequência de atividades que envolvesse a exploração das funções de variável real por meio do uso da tecnologia móvel; averiguar se em um ambiente coletivo que envolvesse ações cooperativas poderia haver construção de conceitos matemáticos sobre funções de variável real por parte dos sujeitos e investigar como o uso de dispositivos móveis auxilia os estudantes participantes na exploração do assunto funções, funções afins e funções quadráticas. O presente texto objetiva concentrar a explanação e análise das produções a partir do estudo das funções afins, feito por um grupo de estudantes participantes.

As diretrizes curriculares nacionais demandam o estudo de funções no Ensino Médio, porém, a BNCC determina o prelúdio do estudo desse conteúdo no nono ano do ensino básico. Como habilidade delimitada pela BNCC sobre funções consta: "Compreender as funções como relações de dependência unívoca entre duas variáveis e suas representações numérica, algébrica e gráfica e utilizar esse conceito para analisar situações que envolvam relações funcionais entre duas variáveis" (BRASIL, 2018, p. 317). Ou seja, o prelúdio do conceito de função é demandado pela BNCC já no nono ano do Ensino Fundamental. Juntando-se a isso o fato de que os estudantes do oitavo ano da escola em que a pesquisa aconteceu oportunamente estudariam tais conceitos, a professora julgou pertinente e proveitoso unir o estudo já feito sobre as equações de 1 ㅇ e 20 grau com o estudo das funções afins e quadráticas. A primeira parte da sequência de atividades envolveu o estudo de "introdução do pensamento com funções", que explorou a ideia de dependência entre variáveis, grandezas, análise e interpretação de gráficos nos mais diversos contextos. 
A sequência de atividades experimentada pelos estudantes envolveu o estímulo ao trabalho coletivo e o uso do smartphone para a exploração gráfica das funções afins. Com o intuito de identificar as contribuições do conceito de cooperação utilizamos as ideias de Jean Piaget sobre o trabalho coletivo. Além disso, buscou-se refletir sobre como a utilização do smartphone pode contribuir no processo de apropriação do conhecimento. Para isso trazemos, no presente artigo, trabalhos que também exploram sobre o uso dessa tecnologia digital no âmbito da Educação Matemática.

A seguir apresentamos a fundamentação teórica utilizada para análise do experimento didático realizado, com ideias sobre a cooperação, apresentada por meio da perspectiva de Piaget (1973) a partir de trabalhos como os de Bona (2012), Gomes e Ghedin (2012), Treviso (2013) e Pinto (2018), os quais também dialogam com esse tema. Sobre o uso do smartphone na Educação Matemática nossa reflexão ocorre a partir dos estudos de White e Martin (2014), Batista (2011) e Moura e Carvalho (2010), os quais discorrem sobre a importância dessa tecnologia e também refletem sobre resultados positivos em sua utilização no campo da Educação Matemática. Em seguida, apresentamos a caracterização metodológica, materiais e métodos, seguidos de uma análise do experimento ocorrido. Por fim, encerramos o texto com as considerações finais, fruto de nossas reflexões as quais ocorreram a partir da experimentação.

\section{Fundamentação teórica}

\subsection{A ideia de cooperação}

O diálogo entre os pares na realização das tarefas se faz importante na construção de reflexões por parte dos estudantes. Assim, a ideia de cooperação contribuiu na elaboração e execução do nosso experimento didático. Essa seção apresenta e reflete sobre a ideia de cooperar e relações com a construção de conhecimento.

Cooperar, segundo Piaget (1973) é agir em comum por meio de novas operações de correspondência, reciprocidade ou complementaridade. Essas características de ações podem emergir em um trabalho em grupo com tarefas que façam os estudantes dialogarem entre si e, a partir de um conjunto de pensamentos, onde todos estejam envolvidos no desenvolvimento dos problemas, possam contribuir na construção da solução. Sobre cooperação, Piaget (1973) apresenta:

A cooperação consiste nela mesma num sistema de operações, de tal forma que as atividades do sujeito se exercendo sobre os objetos, e as atividades dos sujeitos quando agem uns sobre os outros se reduzem na realidade a um só e mesmo sistema de conjunto, no qual o aspecto lógico são inseparáveis na forma como no conteúdo. (PIAGET, 1973, p.103).

A partir desse sistema de operações que consiste a cooperação torna-se necessário observar aspectos para identificá-la nos diálogos entre os pares. Com isso, busca-se por evidências do exercício reflexivo intelectual nas trocas entre os pares, as quais para Piaget (1973) podem ser observadas a partir das ações, sejam individuais ou coletivas. As trocas de ideias entre os sujeitos são comumente utilizadas por Piaget (1973) como trocas de proposições, sendo proposição um "ato de comunicação" (PIAGET, 1973, p. 106). Os equilíbrios de troca, ou seja, "as características do estado no qual os interlocutores se encontrarão de acordo ou intelectualmente satisfeitos" (PIAGET, 1973, p. 108) ocorrem em meio ao ato de cooperação. Com isso, em caso de não haver acordo por parte dos sujeitos 
sobre alguma proposição, não haverá equilíbrio de troca, fazendo com que a discussão sobre certo assunto prossiga, sem que uma solução parcialmente estável esteja construída.

Piaget (1973) questiona como uma troca de ideias vai se constituir em cooperação de pensamento. Para isso, devemos estabelecer os equilíbrios de trocas, já exemplificados anteriormente e, após, estruturar um conjunto de regras que forma uma lógica formal. Sobre os equilíbrios de troca, Piaget (1973, p. 108) menciona que são necessárias três condições que os comportam. São elas:

1a Condição: Dois sujeitos devem estar em uma mesma escala de valores (regras morais e jurídicas etc.) intelectuais, apresentados por meio de símbolos comuns homogêneos. Essa escala deve comportar três características complementares: a) uma linguagem; b) um sistema de fundamentos definidos entre indivíduos, mesmo que convirjam inteiramente ou divirjam em parte, mas que seja possível traduzir esses fundamentos de um sistema de um sujeito para o sistema do outro; c) certo número de proposições pondo estes fundamentos em relação, admitidos em acordo, que também valham de referência em caso de discussão entre os sujeitos.

2a Condição: Igualdade geral dos valores em jogo nas variações de preposições em que Piaget (1973) enfatiza que deve haver: a) o acordo sobre os valores reais e virtuais; e b) a conservação das proposições reconhecidas. Sem acordo, não há equilíbrio e as discussões só são possíveis se houver as conservações.

3a Condição: Possibilidade de retornar sem cessar às validades reconhecidas anteriormente, ou seja, é a atualização possível em todo o tempo dos valores virtuais. Esta condição causa reversibilidade (compreender pontos de vista diferentes), e também a reciprocidade (concordar com diferentes pontos de vista).

Camargo e Becker (2012, p. 536) referenciam o que é valor para Jean Piaget, segundo as autoras, para Piaget, o valor "é individual e construído através de reflexões que o sujeito realiza quando contrasta o sentimento e a diferenciação que é capaz de fazer do outro com quem se relaciona nas trocas socais". Ou seja, na primeira condição do equilíbrio de troca, os sujeitos devem ter domínio dos mesmos "conhecimentos", por exemplo, em sala de aula, os estudantes de uma mesma turma podem estar em uma mesma escala de valores para o início das trocas de proposições. Assim, a partir da existência da primeira condição, entendemos que a segunda, que seria a igualdade de valores, o acordo entre essas possíveis trocas de proposições que pode ocorrer entre os sujeitos e a terceira condição que é a reciprocidade e reversibilidade podem acontecer e acarretar os equilíbrios de troca.

Piaget (1973), ainda destaca que essas três condições acontecem somente em trocas cooperativas. Em casos em que o egocentrismo ou coação por parte dos sujeitos surgem, o equilíbrio não é atingido. Nas palavras do autor: "O estado de equilíbrio, tal como é definido pelas três condições precedentes, está assim subordinado a uma situação social de cooperação autônoma, fundamentada sobre a igualdade e a reciprocidade dos parceiros" (PIAGET, 1973, p. 110). Em consonância ao que Piaget (1973) comenta sobre o estado de equilíbrio em ações cooperativas, Oliveira (2019) enfatiza que para a cooperação existir nas salas de aulas é necessário "desfazer-se do egocentrismo intelectual e moral, libertar-se das coações sociais e criar um ambiente em que as relações sejam simétricas por meio da reciprocidade"(OLIVEIRA, 2019, p. 155). Nessa ótica, o papel do professor em um ambiente permeado por ações cooperativas é o de mediação das atividades dos estudantes, agindo como um "especialista, um tutor, um guia que opera com as crianças sem impedir a liberdade 
da criança e nem proibir seus primeiros passos em direção à autonomia" (OLIVEIRA, 2019, p.155).

Logo, entendemos que nas aulas de matemática, a cooperação pode ser estimulada a partir de atividades que valorizam a ação em conjunto dos estudantes. Nessas tarefas a troca de pensamentos e reflexões entre os sujeitos oportuniza que a cooperação conduza à aprendizagem. A partir de uma busca na literatura sobre a temática "cooperação em aulas de matemática" encontramos autores que refletem sobre tal possibilidade. Bona (2012) enfatiza que a cooperação é um processo de aprendizagem que pode criar novas realidades e entendimentos sobre um assunto de matemática. Gomes e Ghedin (2012) expõem o uso das ideias de Jean Piaget ao analisar experimentações que sejam feitas em sala de aula. Os autores destacam que o professor deve respeitar o momento em que o estudante esteja pronto para aprender determinado conteúdo. Para isso, o professor pode proporcionar atividades em que os sujeitos sejam ativos no seu processo de aprendizagem, equilibrando o que já conhecem e o que é novo para conhecer por meio do diálogo e relação com o outro. Desse modo convergirmos e entendemos que, "o enfoque dado por Piaget às relações sociais resulta em implicações para a educação escolar no sentido de secundarizar a função do professor e defender que o aluno deva aprender a aprender" (TREVISO, 2013, p. 13).

Pinto (2018), em sua pesquisa analisou como a cooperação entre os estudantes oportuniza momentos de aprendizagem matemática desde que mediada pelo professor em sala de aula. Segundo a autora, pelo fato dos estudantes terem trabalhado em grupos com a mediação do professor, durante a aplicação de seu experimento didático isso fez com que uma série de diálogos emergisse e esses, conduziram à construção de argumentos para a solução dos problemas em estudo. Sobre o trabalho coletivo, Pinto $(2018$, p.73) menciona que "ao oportunizar momentos de compartilhamento e enfrentamento de situações de forma conjunta é bom para o grupo e também é benéfico para o sujeito".

A partir das ideias apresentadas nessa seção sobre cooperação, manifestadas por meio de ações que potencializam e empreendem o desenvolvimento pessoal considerou-se apropriado utilizar esse referencial teórico no presente estudo, os quais podem produzir reflexões pertinentes ao campo da Educação Matemática. A próxima seção explana sobre as potenciais contribuições da tecnologia digital, a partir do uso do smartphone, para a Educação Matemática.

\subsection{O uso de smartphones na Educação Matemática}

Viver sem um smartphone com acesso à internet é como se estivéssemos desconectados do mundo (BAIRRAL, 2017). Dentro da sala de aula, cada vez mais, presenciamos os jovens com seus smartphones (WHITE; MARTIN, 2014). Uma análise sobre as potencialidades para a aprendizagem a partir da utilização dessas tecnologias traz para a sala de aula e para a vida do estudante, contribuições tais como as apresentadas na Base Nacional Comum Curricular (BNCC):

Tal valorização possibilita que, ao chegarem aos anos finais, eles possam ser estimulados a desenvolver o pensamento computacional, por meio da interpretação e da elaboração de algoritmos, incluindo aqueles que podem ser representados por fluxogramas. (BRASIL, 2018, p. 528).

Consideramos a utilização dos smartphones no âmbito dessa pesquisa uma ação importante, pois eles possibilitam para além da mobilidade do sujeito. Além disso, 
entendemos que ao utilizar tais dispositivos móveis de alguma maneira ameniza-se o problema que as escolas enfrentam sobre a falta de estrutura, em particular a existência de laboratórios de informática, conforme mencionado por Batista (2011).

Ademais, uma das características facilitadoras e que possa acarretar em uma aprendizagem é a interação touchscreen fornecida pelos smartphones uma vez que a "importância do toque e gesto por usar os dispositivos móveis e outros dispositivos touchscreen, vemos um melhor aprendizado sobre as aplicações da matemática das ações nesse espaço como recursos críticos" (WHITE; MARTIN, 2014, p. 9). Ou seja, o contato do estudante com seu smartphone pode ser um catalisador na direção da construção de conhecimentos.

As salas de aula, atualmente, são caracterizadas por estudantes inquietos. Movimentação e conversas desses sujeitos estão presentes no ambiente de aprendizagem (CORDEIRO, 2015). Devido a essa agitação, devemos repensar as formas de estudar matemática. Como os dispositivos móveis estão presentes na vida desses estudantes, o dia a dia das escolas passa a ser um espaço composto por tecnologias digitais, o modo Online, e o modo Offline onde o quadro e giz estão presentes também (CORDEIRO, 2015). Além disso, Cordeiro (2015) comenta que:

(...) os alunos já são seres híbridos, suas práticas estão intimamente relacionadas com a conectividade (comunicação, redes sociais, vídeos, fotografias), e passam a evadir-se simbolicamente de um cotidiano que não oferece experiências relacionadas à cultura digital (produção, vivência digital online e off-line). Eles criam seus próprios territórios informacionais, compartilhados ou não como seus professores e escola. Eles controlam esses territórios a partir do momento que detêm suas senhas e decidem seus grupos de compartilhamento. (CORDEIRO, 2015, p. 296).

O tema tecnologia móvel permeia as práticas de ensino da matemática, pelo fato desses estudantes estarem constantemente conectados. Atualmente, lidamos com uma geração conectada à internet por meio de smartphones e essa geração é formada por jovens que cada vez mais utilizam e se apropriam dessas tecnologias digitais (SONEGO, 2019). Consideramos possível trazer o uso desses recursos tecnológicos contemporâneos para o desenvolvimento de atividades dentro das salas de aula. Porém, Sonego (2019) afirma que a inclusão desses dispositivos requer planejamento e conhecimento das funcionalidades desses recursos tecnológicos por parte dos educadores. Sobre o papel do professor perante esses recursos digitais que podem ser implementados em sala de aula cabe a ele arriscar, Silva (2018, p. 22) considera que "se o docente arrisca, experimenta e de certa forma tenta inovar, rompe-se com a ideia unidirecional do ensino que prioriza a transmissão em oposição a construção de conhecimentos". Consideramos que explorar as tecnologias móveis que já estão presentes no cotidiano dos estudantes possa auxiliar na busca pelo conhecimento dos mesmos.

Existe a presença dos smartphones na sala de aula em que a pesquisa aconteceu, para utilizar as tecnologias móveis, o professor precisa desenvolver e se apropriar das potencialidades que esses recursos digitais têm a oferecer para implementá-la em sala de aula (FRANKLIN e PENG, 2008). Além disso, quando os professores mencionam sobre as dificuldades de às vezes pensarem que os estudantes vão ter dificuldades em manusear e utilizar essas tecnologias pode impedir que as mesmas sejam exploradas nas aulas de 
matemática. Nesse sentido, Franklin e Peng (2008) comentam sobre o início de sua pesquisa sobre os estudantes produzirem vídeos sobre conceitos matemáticos utilizando computadores. Eles discorrem que o primeiro comentário dos educadores, participantes da pesquisa, foi de que os estudantes teriam muita dificuldade em manusear os programas de criação de vídeo, o que foi contestado no decorrer da prática, os sujeitos utilizaram bem e sem dificuldades os softwares propostos. Sustentando o que Franklin e Peng (2008) mencionaram sobre o receio dos professores em utilizar as tecnologias em sala de aula, Higuchi (2011), comenta que apesar da presença de celulares nesse ambiente, entre os estudantes no Brasil, eles não são incorporados e utilizados em atividades pedagógicas, inclusive, como resultado de sua pesquisa, os professores entrevistados comentam que desconhecem as possibilidades de aplicação desses dispositivos móveis na educação.

$\mathrm{O}$ ato do toque na tela ao interagir com um dispositivo móvel como o smartphone pode oportunizar ao sujeito descobertas e aprendizagens além de dinamizar o ensino, promovendo novas explorações conceituais em sala de aula conforme destaca Bairral (2017). Sobre a construção do conhecimento matemático e a interação com o dispositivo móvel:

Quando um sujeito manuseia um dispositivo móvel em tarefas matemáticas, cabe ressaltar a importância de considerar a conjunção (gestos+toques+escrita+construção-na-tela) na construção do conhecimento matemático, sem priorizar uma delas, geralmente, a escrita. Haverá momento em que a fala ou a manipulação em tela serão mais propícias a descobertas e refinamentos conceituais. Em outras circunstâncias, as diferentes formas de registros, inclusive a escrita e as construções no software, poderão ser igualmente úteis. (BAIRRAL, 2017, p.105).

Com isso, ao trazer para a sala de aula recursos tecnológicos que são presentes na vida dos estudantes pode contribuir e ser uma "fonte de motivação dos alunos pela escola e pelo processo de ensino e aprendizagem" (MOURA; CARVALHO, 2010, p.1006). Acrescenta-se a isso as potencialidades que os dispositivos móveis propiciam aos estudantes, tal como Martins et al (2018) verificaram por meio de pesquisa, em que os smartphones se apresentaram como um recurso para novas formas de interação, construção e desenvolvimento do conhecimento por parte dos sujeitos. Para que essa interação, estudante com smartphone, ocorra de forma efetiva é necessário que os sujeitos estejam com essas tecnologias em mãos durante a realização das atividades matemáticas, "pois é dessa maneira que seu potencial para qualificar a aprendizagem pode ser aproveitado.". (STORMOWSKI, 2018, p. 109).

Desta forma, possibilitar aos estudantes vivenciar experiências matemáticas com uso da tecnologia em sala de aula, em particular com o smartphone, pode aumentar seu interesse em aprender e consequentemente colaborar no seu processo de construção dos conhecimentos. Com isso, a partir das reflexões dessa seção entendemos que espaços cooperativos e tecnológicos possam ter uma incomensurável riqueza, e tornam-se aliados à construção de conhecimentos e saberes pelos estudantes.

\section{Fundamentos metodológicos}

O objetivo da sequência de atividades realizada com o grupo de estudantes participantes do experimento didático foi identificar elementos de cooperação entre os pares que ocorressem por meio da utilização de seus smartphones durante a exploração das atividades que versavam o estudo da função afim. $O$ estudo aqui apresentado trata-se de um 
recorte de uma pesquisa de mestrado em Ensino de Matemática, com a produção dos dados ocorridos ao final de 2019 em uma escola localizada em Porto Alegre (RS). A pesquisa de mestrado, já finalizada, objetivou produzir reflexões envolvendo a temática da cooperação a partir do uso de smartphones no estudo das funções, funções afins e funções quadráticas por estudantes do Ensino Básico. Neste artigo apresentamos uma das etapas da produção dos dados. Entendemos que a caracterização metodológica no presente estudo esteja alinhada com a perspectiva qualitativa, conforme propõe Flick (2009):

Os aspectos essenciais da pesquisa qualitativa consistem na escolha adequada de métodos e teorias convenientes; no reconhecimento e na análise de diferentes perspectivas; nas reflexões dos pesquisadores a respeito de suas pesquisas como parte do processo de produção de conhecimento; e na variedade de abordagens e métodos. (FLICK, 2009, p. 23).

Convergente a isso, Bogdan e Biklen (1994) elencam as cinco características da pesquisa qualitativa, as quais percebemos que também sejam características da forma de trabalho realizada. São elas: a fonte de dados é o ambiente natural dos sujeitos (característica 1); a pesquisa qualitativa é descritiva (característica 2); é de interesse para a análise o todo do processo da pesquisa (característica 3); a análise dos dados ocorre de forma indutiva (característica 4) e há de se verificar a importância do significado das análises (característica 5).

Durante a realização do experimento de ensino foram produzidos áudios de um grupo formado por três estudantes que com seu próprio smartphone, registraram suas discussões. Iremos identificá-los no presente texto por A3, A4 e A5 com a finalidade de preservar suas identidades. A escolha do grupo de estudantes se deve ao "pense curto" (BOGDAN; BIKLEN, 1994, p.173) proposto pelos autores e que consiste em considerar um número de sujeitos o qual a realização e exposição das transcrições dos áudios exponham resultados que sejam relevantes para uma reflexão concernente à pesquisa.

As atividades foram elaboradas e utilizadas por estudantes do oitavo ano de uma escola de gestão privada localizada em Porto Alegre (RS) em novembro de 2019. Anteriormente à realização do experimento, os estudantes receberam o Termo de Consentimento Informado para que seus responsáveis pudessem autorizar sua participação na pesquisa e um termo de assentimento assinado pelos próprios estudantes, concordando na participação da mesma. Pelo fato dos grupos de estudantes terem convergido para discussões similares às evidenciadas nesse artigo, escolhemos para exposição e análise no presente texto os dados produzidos por um grupo de estudantes que manifestou um debate com elementos os quais entendemos contribuir no campo de reflexão inerente à pesquisa em Educação Matemática. A seguir apresentamos integralmente cada uma das atividades utilizadas nessa etapa da pesquisa, na forma de figuras, com o objetivo de proporcionar um melhor entendimento para o leitor sobre as análises produzidas a partir dos dados construídos pelo grupo de estudantes. 


\section{Figura 1 - Problema 1.}

As sacolas plásticas sujam florestas, rios e oceanos e quase sempre acabam matando por asfixia peixes, baleias e outros animais aquáticos. No Brasil, em 2007, foram consumidas 18 bilhões de sacolas plásticas. Os supermercados brasileiros se preparam para acabar com as sacolas plásticas até 2016 . Observe o gráfico a seguir, em que considera a origem como o ano de 2007.

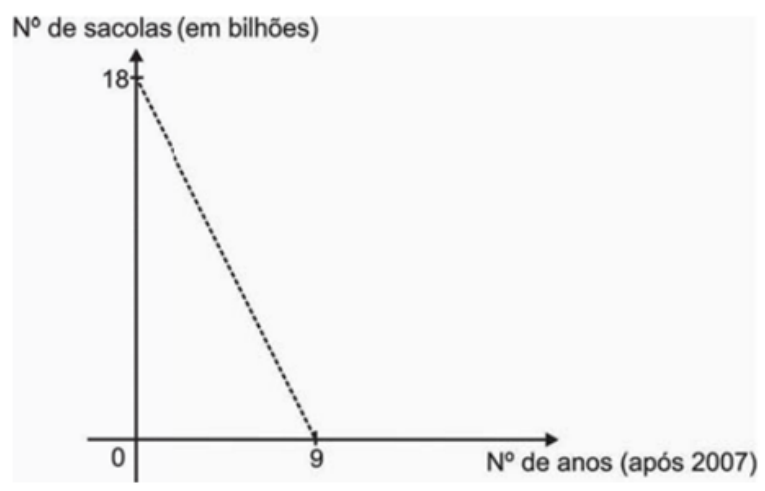

a) De acordo com as informações, quantos bilhões de sacolas plásticas serão consumidos em 2011? Explore.

b) Explore com seu grupo e indique as possíveis causas dessa diminuição do uso de sacolas plásticas.

c) Em 2019, o número do consumo de sacolas plásticas foi erradicado? Explore com seu grupo e discutam como o consumo de sacolas plásticas situa-se em suas localidades, atualmente. O que está sendo feito para que esse consumo seja reduzido?

Fonte: Arquivo pessoal.

Figura 2 - Problema 2.

Uma relação curiosa é sobre como obter uma estimativa para o número do sapato que usamos. A partir da medida do comprimento do pé (x), é possível obter o número do calçado a ser usado por meio da relação:

$$
N(x)=\frac{5 x+28}{4}
$$

Se necessário utilize arredondamentos para "mais".

a) Meça o seu pé e verifique se a função fornece o número de calçado que você de fato usa.

b) A pessoa que tem o comprimento do pé com $28 \mathrm{~cm}$ usa qual numeração de calçado de acordo com a relação $\mathrm{N}$ (x)?

c) Um calçado número 36 está relacionado com um pé de qual medida?

d) Faça um esboço do gráfico de $\mathrm{N}(\mathrm{x})$ no GeoGebra e tente explicar o que seria N(0).

Fonte: Arquivo pessoal.

Figura 3 - Atividades sobre a função $f(x)=a x+b$.

Considere: $f(x)=a x+b$.

1) Plote no campo de entrada do aplicativo: $f(x)=a x+b$.

2) Varie o controle deslizante $a$. O que você pode afirmar sobre o movimento da imagem na tela? Explique.

3) Varie o controle deslizante $b$. O que você pode afirmar sobre o movimento da imagem na tela? Explique.

4) Qual o papel desempenhado pelo parâmetro $a$ ? Explique.

5) Qual o papel desempenhado pelo parâmetro $b$ ? Explique.

Definição: Uma função $f$ real possui raiz real, quando $f$ possui valores reais para $x$ tal que $f(x)=0$.

6) No aplicativo GeoGebra Graphing Calculator desenhe as funções abaixo e encontre suas raízes. Explique seu processo de obtenção.
a) $f(x)=x+3$
b) $g(x)=x-9$
c) $h(x)=2 x+1$
d) $i(x)=\frac{x}{4}-5$

7) Analisando as funções $f(x), g(x), h(x)$ e $i(x)$ do exercício anterior, você consegue determinar as raízes das funções sem efetuar nenhum tipo de cálculo? Explique.

8) Que definição poderíamos adotar para a função estudada? Quais suas características? Explique.

Fonte: Arquivo pessoal. 
A próxima seção destina-se para apresentar por meio de transcrições, os áudios gravados pelos estudantes durante a exploração das atividades mostradas na sequência de figuras anterior. Durante a explanação ocorre uma reflexão nossa, enquanto pesquisadores, frente ao referencial teórico mostrado na seção dois, a qual tenta mostrar que seja convergente e enriquecedor no âmbito da Educação Básica propor formas de trabalho que sejam coletivas e façam uso da tecnologia, alinhando-se assim ao alcance do objetivo da pesquisa explanado na introdução do presente texto.

\section{Apresentação dos dados e debate}

Esta seção objetiva apresentar e refletir por nossa parte sobre as manifestações de ações cooperativas pelos estudantes, e também observar de que forma o smartphone auxiliou na construção dos diálogos entre os pares. Os áudios produzidos pelos estudantes durante o experimento didático constituíram uma fonte para análise do ocorrido em sala de aula. $A$ partir da escuta e das análises feitas foi possível compreender a importância de possibilitar em sala de aula momentos para o compartilhamento de ideias e construção de conhecimentos pelos estudantes, necessários ao atual contexto de sociedade o qual todos estão inseridos. Para localizar o leitor quanto aos destaques feitos nos trechos transcritos, ao longo da exposição dos diálogos define-se a identificação em negrito e utilizaremos as legendas [COOP] para indícios de cooperação e [COOP + TDM] Cooperação e Tecnologia Digital Móvel para indícios de cooperação atuando com o aplicativo GeoGebra Graphing Calculator. A exposição dos trechos transcritos será permeada com nossa análise e debate sobre a produção dos estudantes. Participaram e produziram os dados expostos nesta seção os estudantes do grupo 2, identificados no presente texto da forma A3, A4 e A5. A atividade foi realizada durante uma aula de matemática e o grupo realizou as gravações em áudio no dispositivo móvel de A3. Os mesmos gravaram durante os 100 minutos de aula.

Quadro 1 - Função Afim. Problema 1. Item (a).

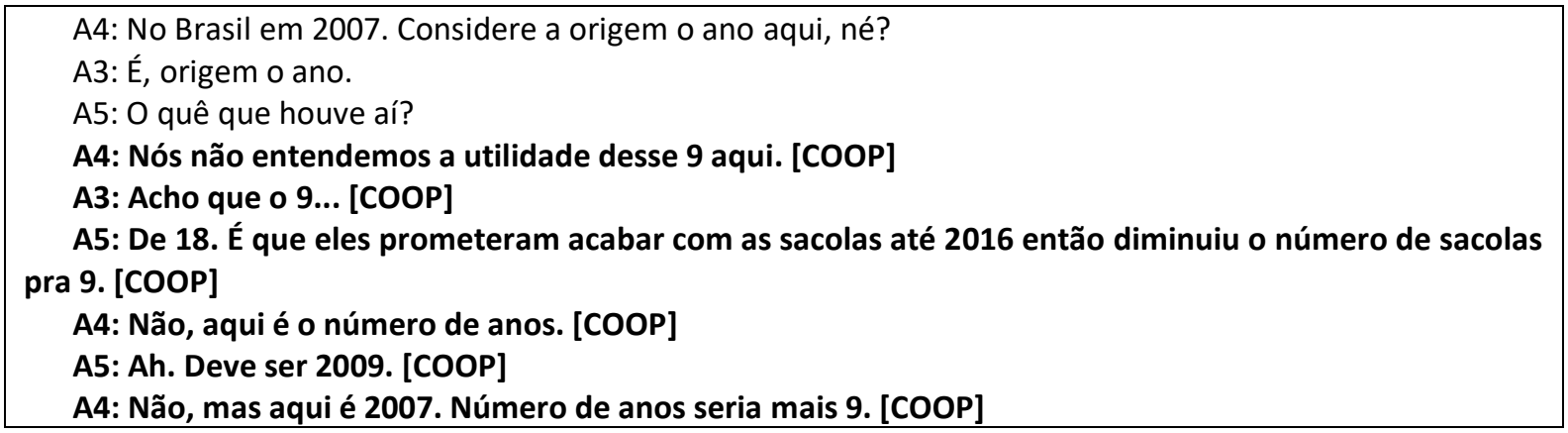

Fonte: Dados da pesquisa.

O trecho grifado no quadro 1 expõe o diálogo entre os estudantes A4 e A5 sobre a análise gráfica. A partir da exposição de opiniões entre os dois estudantes, percebemos que a estudante A4 está discordando do estudante A5, perante o significado do número 9, exposto no gráfico. Abaixo exemplificamos o mesmo e no quadro 2 analisamos a continuação do diálogo do grupo. 
Quadro 2 - Função afim. Problema 1. Item (a).

A4 e A5: Ah, 2016.Tá, que eles iam abolir o...

A5: Tá, mas depois daqui.

A4: Eu não sei nem o que. Ah de acordo com as informações... A gente deveria construir esse gráfico no GeoGebra?

A3: Aham.

A3: Não tem um triângulo aqui, não? Podia ter um triângulo pronto. [COOP+TDM]

A4: Ãhn. Acho que a gente deveria fazer uma função, não? [COOP+TDM]

A3: Vamos colocar uma semirreta nesse gráfico. [COOP+TDM]

A5: $B$, não se arrasta nada no GeoGebra.

A3: É que eu preciso ir pra cima.

A4: Espera, espera.

A3: Tentar mexer no gráfico. [COOP+TDM]

A4: Tá, ãhn, botar uma linha aí. [COOP+TDM]

A3: Uma reta do gráfico. [COOP+TDM]

A4: Apenas um triângulo retângulo, sabe? [COOP+TDM]

A3: Então. [COOP+TDM]

A5: Cadê a hipotenusa, cadê os catetos? [COOP+TDM]

A3: Então tá, vamos dizer assim. Vamos dizer que isso aqui é de 2007, 2009, 2010, 2011. Tá. Então 10 bilhões de sacolas.

A3: É que assim, eu não sei a ordem desse negócio ainda.

A4: Mas a gente só precisa de algo pra gente conseguir ver qual é a relação entre eles, sabe? Tipo, em qual pontinho ele se encontraria aqui. Porque assim, olhando, a gente não tem esse dado, mas se a gente criar esse gráfico, gráfico a gente saberia, então a gente... [COOP+TDM]

Fonte: Dados da pesquisa.

No início do diálogo do quadro 2, percebemos que os estudantes A4 e A5 expressam seu entendimento sobre o que seria o 9 exposto no gráfico. Notamos que o estudante A4 pode ter auxiliado na conclusão do estudante $A 5$ ao discutirem sobre o que seria o número 9 , onde parece ser consensual o acordo sobre o significado do número. Assim, expusemos uma troca de ideias que segundo Piaget (1973), por meio do acordo entre os dois interlocutores houve de certa forma cooperação.

Ainda no quadro 2, os trechos seguintes expressam as primeiras ideias dos estudantes para elucidarem o item (a) do problema 1. Eles utilizam o aplicativo GeoGebra Graphing Calculator para auxiliá-los na construção de uma resolução para o problema. A ação de explorar o aplicativo para tentar obter êxito na atividade vem ao encontro com o que Bairral (2017) comenta que no ato do toque na tela de smartphones são possibilitadas novas descobertas, abordagens que consequentemente implicam em alguma aprendizagem.

Enquanto os estudantes estão manipulando o aplicativo para reproduzir o gráfico do problema, eles comentam sobre utilizar o conhecimento dos lados do triângulo retângulo para um início de resolução. Então, A3 indica a resposta e A4 argumenta que eles precisariam do gráfico do problema no GeoGebra para que pudessem encontrar exatamente o ponto que expressa o número de sacolas em 2011. Porém, a discussão parece ter ficado em aberto, pois eles prosseguiram sem argumentos e registraram 10 bilhões como resposta. 
Quadro 31 - Função afim. Problema 1. Item (b).

A4: Tá. Explore com seu grupo e identifique as possíveis causas dessa diminuição.

A3: Quê?

A4:Possíveis causas dessa diminuição?

A5: Causas: os mercados começarem a diminuir o uso. [COOP]

A4: Ãhn.

A5: $E$ as pessoas começarem a usar sacolas reutilizáveis. Tipo. [COOP]

A4: Sim, mas eu acho que foi uma medida do governo, não? Que se acabasse em 2016, então. [COOP]

A5: Coisa que não aconteceu, porque até hoje eu uso sacola plástica. [COOP]

A4: É, então. Ãhn, então seriam: conscientização da população e leis, leis não. Medidas governamentais que previnem... [COOP]

Fonte: Dados da pesquisa.

No quadro 3, percebemos como os estudantes A4 e A5 encontram-se em correspondência ao analisarem as causas da diminuição do número de sacolas plásticas. Essa correspondência pode ser considerada, segundo Piaget (1973), como possível ação cooperativa. Além disso, Piaget (1973) comenta que desenvolver reflexões contempla a cooperação entre os sujeitos e os mesmos se soltam do seu pensamento individual inicial.

Quadro 4 - Função afim. Problema 1. Item (c).

A4: Ó. Em 2019 o número do consumo de sacolas plásticas foi erradicado?

A4, A3 e A5: Não. [COOP]

A4: Ãhn, o uso de sacolas plásticas ainda é frequente? E pode-se dizer que a única opção. Se não levar as tuas. [COOP]

A3: É. [COOP]

A5: E que é uma incomodação braba, porque tu vai entrar dentro do troço e... [COOP]

A4: É, eu brigo com meus pais pra levarem sacolas reutilizáveis. [COOP]

A3: É frequente e.. [COOP]

A4: Ãhn. E quase como a única opção. [COOP] Tá. O que está sendo feito para que esse consumo seja reduzido? Ãhn.

A5: A gente já botou né.

A4: Assim, nada, mas campanhas, tem mais campanhas de plástico e essas coisas, mas não é nenhuma medida governamental, tipo lei, é só tipo uma galera falando usa sacola de pano, sabe? [COOP]

A3: É, nada... [COOP]

A4: Nada muito oficial e nada muito. Tá, enfim. [COOP]

Fonte: Dados da pesquisa.

No quadro 4, notamos que há troca entre os pares. O trio de estudantes está discutindo sobre o consumo de sacolas plásticas atualmente. Como há trocas, podemos classificá-las como trocas de equilíbrio já que elas obedecem às três condições de Piaget (1973) para estarem em equilíbrio e estabelecerem a cooperação: 1a Mesma escala de valores: percebemos pelos diálogos dos sujeitos que eles estão em um mesmo nível de conhecimento sobre o ambiente em que estão emersos. 2a Igualdade de valores: Os sujeitos demonstram acordar uns com os outros sobre o uso das sacolas plásticas no meio ambiente. 3a possibilidade de reciprocidade, concordância com os pontos de vista uns dos outros.

Quadro 5 - Função afim. Problema 2. Item (a).

A5: Tá tudo errado, eu uso 42. Mas eu uso sapato 40, às vezes, Tá certo, tá certo.

A4: Ah, a estimativa é correta.

Fonte: Dados da pesquisa. 
Como exposto no quadro 5 , os estudantes realizaram a medida do pé de A5 e concluíram que a estimativa da relação do problema estava correta. Neste quadro não percebemos trocas de pensamentos para possível cooperação.

Quadro 6 - Função afim. Problema 2. Item (b).

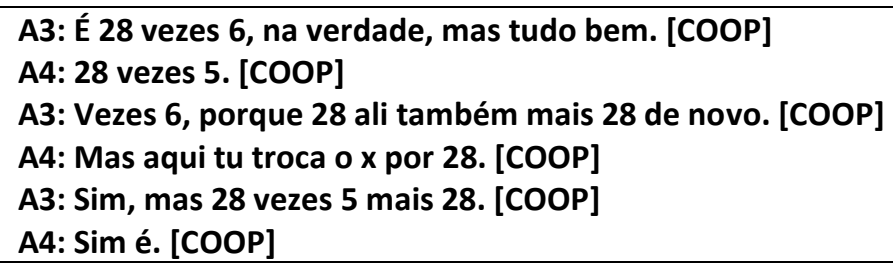

Fonte: Dados da pesquisa.

Como exposto no quadro 6, as estudantes A4 e A3 estão dialogando sobre como resolver o problema 2 , item (b), em que as mesmas têm que substituir na relação expressa a incógnita $x$ por 28. $O$ estudante $A 3$ expõe seu modo de calcular e A4 discorda, então A3 explica seu raciocínio, $A 4$ concorda com o modo de resolução de $A 3$, porém, não temos indícios de que A4 possa ter entendido a explicação exposta por A3. Ainda assim, a troca de proposições, segundo Piaget (1973) pode significar que os indivíduos estejam convergindo para o equilíbrio.

Quadro 7 - Função afim. Problema 2. Item (c).

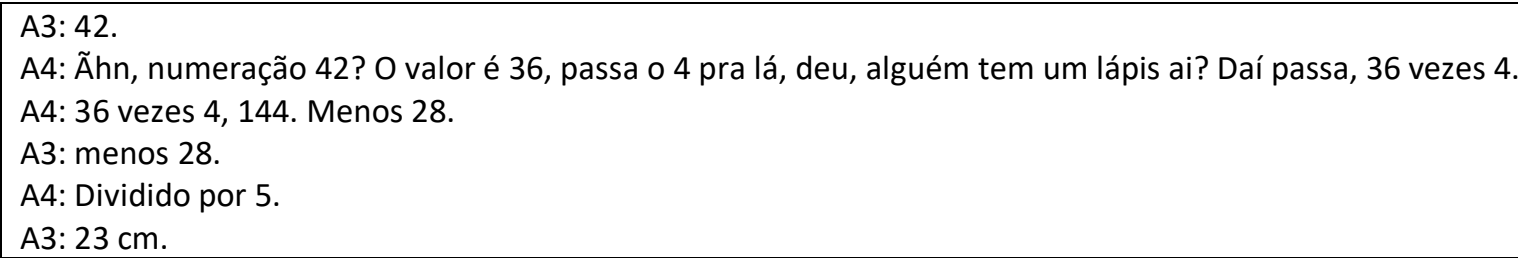

Fonte: Dados da pesquisa.

Como exposto no quadro 7, as estudantes A4 e A3 estão conversando sobre como estão resolvendo o item (c) do problema 2. Descrevendo os cálculos, sem apresentar dificuldades, as mesmas terminam ao evidenciar a resposta de $23 \mathrm{~cm}$. Aqui não iremos pontuar nenhuma característica apresentada nos aportes teóricos, pois não encontramos.

Quadro 8 - Função afim. Problema 2. Item (d).

A4: Faça um esboço do gráfico do e de $x$, não sei como pronuncia isso.

A3: Deve ser um número no geogebra tem que colocar o que seria...

A4: $N$ zero. Se $x$ for zero vai dar.

A3: Zero, não tem muita.

A4: Vai ser 28 dividido por 4.

A3: É.

A4: Tá, enfim.

Fonte: Dados da pesquisa.

No quadro 8, os estudantes não explicitam o esboço do gráfico. Os trechos grifados expressam duas conclusões entre $A 4$ e $A 3$, porém entre a mudança das respostas, não houve indícios de debate entre as duas. Percebemos que A4 começa a analisar, A3 indica sua resposta já indicando que seria zero e A4 expõe a sua resposta de que seria " 28 dividido por 
4". Não há conclusão ou exploração sobre o porquê dessa forma de encaminhamento para a solução e o grupo segue para a próxima atividade.

Sobre a atividade de plotar o gráfico da função (atividades 1, 2 e 3) a partir da observação constatamos que na atividade 1, A3, A4 e A5 não demonstraram dificuldades em plotar a função $\boldsymbol{f}(\boldsymbol{x})=\boldsymbol{a x}+\boldsymbol{b}$ no GeoGebra Graphing Calculator. Nas atividades 2 e 3 os estudantes descreveram o que observaram na tela do smartphone. Na variação do controle deslizante " $a$ ", o gráfico fez movimentos nos sentidos horário e anti-horário, os três estudantes compartilharam da mesma opinião e na atividade 3 , o trio descreveu o movimento do gráfico como para baixo e para cima, quando variaram o controle deslizante " $\mathrm{b}$ ". Percebemos ao interagirem com a tela do smartphone conseguiram visualizar o efeito de variar um dos parâmetros da função afim, sendo convergente ao que White e Martin (2014) discorrem sobre a importância da utilização de smartphones e como eles podem auxiliar na aprendizagem dos estudantes.

Quadro 9 - Função afim. Atividade 4.

A4: Qual é o papel desempenhado pelo parâmetro a? [COOP+TDM]

A3: Da medida em $x$ ? Do eixo $x$ ? Não sei. [COOP+TDM]

A4: Pode ser. [COOP+TDM]

A3: Pode ser? [COOP+TDM]

A4: Pode ser. [COOP+TDM]

Fonte: Dados da pesquisa.

Como expomos nos trechos grifados do quadro 9 o estudante $A 3$, com indícios de dúvidas em sua resposta, questiona A4 se o parâmetro " $a$ " era o valor do gráfico no eixo $x, \mathrm{~A} 4$ sem questionar $A 3$ responde que poderia ser essa a resposta. Novamente, no quadro 10 , os sujeitos exploraram o papel de um dos parâmetros da função, agora atribuindo uma hipótese a ele, a qual pode ser verificada via ação no GeoGebra, trazemos a discussão de Bairral (2017) que menciona o ato do toque na tela do celular como um elemento que possa oportunizar aos sujeitos novas descobertas e aprendizagens, pois os estudantes manipularam o controle deslizante com seus toques na tela projetando a variação do gráfico da função no smartphone.

Quadro 10: Função afim. Atividade 5.

A3: Qual é o papel desempenhado pelo parâmetro $b$ ?

A4: Da medida ao eixo. [COOP+TDM]

A3: Eixo y? Vamos ver. [COOP+TDM]

A4: Não, é que ele mexe nos dois, ó. [COOP+TDM]

A3: Ah ele mexe nos dois. [COOP+TDM]

A4: Então...ambos mexem nos dois, né. [COOP+TDM]

A3: É. Esse aqui, não, esse aqui só mexe no x. 0 a, porque o b tá pretinho ali o outro não. [COOP+TDM] A4: Ah, verdade. Tá então ele dá a medida ao eixo y. [COOP+TDM]

Fonte: Dados da pesquisa.

A partir dos trechos grifados no quadro 10 percebemos que A4, ao variar o controle deslizante " $b$ ", conclui que tanto o controle deslizante " $a$ " quanto " $b$ " influenciam nas posições de intercepto de $x$ e $y$ no gráfico. A partir desse apontamento, A3 concorda, mas na próxima fala grifada discorda de A4, apontando que o valor de x não altera e sim o valor de y. Por fim, A4 concorda com o argumento expresso por A3. Nesse trecho, entendemos que a utilização do aplicativo colaborou com o diálogo entre os pares, no sentido de que a partir do movimento na tela as hipóteses elaboradas pelos estudantes terem sido colocadas em teste, 
assim como destaca White e Martin (2014) expõe sobre a utilização de dispositivos touchscreen pode potencializar a construção e entendimento de conceitos matemáticos.

Ao mesmo tempo, o aplicativo foi o meio para que os argumentos fossem expostos e discutidos. Piaget (1973) afirma que se temos trocas de proposições e as mesmas encontramse em equilíbrio, temos cooperação, é o que está sendo exposto no quadro 10 que a partir das ideias expostas por A3 e A4. Por fim, entendemos que há o estabelecimento de um acordo e que converge para a posição de que o parâmetro " $b$ " tem alguma relação com a posição marcada no eixo $y$.

Quadro 11 - Função afim. Atividade 6.

A4: Voltando. Tá, então seria -3. Tem que escrever aqui?

A3: Ah verdade.

$A 4: x=-3$. A gente tá achando um número pra zerar o $x$. Pra ser $f(x)=0$. Analisando...

A3: Sim.

Professora aponta para o gráfico e pergunta:

Professora: Onde é a raiz dessa função?

A3 aponta para o eixo $x$.

Professora: Tá, e x é quanto?

A3: 9.

Professora: $\mathrm{x}$ é 9?

A3: -9

A4: x é 9.

Professora: Onde está o eixo x e o eixo y?

A4: Tá o eixo y tava ali (vertical) e o eixo $x$ ta aqui (horizontal). [COOP+TDM]

Professora: Tá, se o eixo y tava ali o $x$ era quanto ali?

A4: -9. [COOP+TDM]

Professora: Se o eixo y era aquele ali quanto que era $0 x$ ?

A3: Zero? [COOP+TDM]

Professora: Zero.

A4: 0 y -9. [COOP+TDM]

Professora: Isso. Se o y tá aqui, vamos tirar o zoom, se o y tá aqui ele ta cortando bem ali no -9 , bem no

eixo y no -9. Logo se o $x$ ta aqui, quanto que é o y nesse caso aqui?

A3: 1. [COOP+TDM]

Professora: 1. Agora se eu coloco meu ponto aqui? Quanto que vai ser meu y?

A3: Zero. [COOP+TDM]

Professora: E o x é quanto?

A4 e A3: 9. [COOP+TDM]

Professora: 0 que o gráfico faz no eixo $x$ ?

A4: Corta. Tá é o número que passa exatamente quando corta o eixo x. [COOP+TDM]

Fonte: Dados da pesquisa.

Os trechos grifados no quadro 11 demonstram a ação da professora pesquisadora. Como já mencionado por Treviso (2013), entende-se que a função do professor seja nesses momentos a de realizar uma mediação para que o estudante aprenda a aprender. Por meio de questionamentos a professora incentiva que A4 e A3 reflitam sobre como deva ser representado o zero de uma função. A partir da análise gráfica as duas estudantes com mediação da professora, continuaram a explorar as atividades com os dados expressos pelos gráficos das funções.

Ainda no quadro 11, as ações cooperativas são evidenciadas, já que há discussão entre os pares. Piaget (1973) enfatiza que a cooperação é um sistema de operações em que as atividades dos sujeitos se exercendo sobre os objetos ou sobre os outros se reduzem a um 
sistema de conjunto. Como expresso no quadro 12, os estudantes agem sobre o aplicativo para que o aplicativo seja o meio para que as discussões emirjam e assim os estudantes agem uns sobre os outros com argumentos que os levam a estabelecer conceitos matemáticos sobre os zeros das funções.

Quadro 12 - Função afim. Atividade 8.

A3: Que definição poderíamos adotar para a função estudada?

A4: Qual definição poderíamos adotar para a função estudada? Ãhn... É meio que isso.

A3: É, é isso.

A4: Não, tá, uma função afim, afim que fala? É aquela que possui uma raiz real. [COOP+TDM]

A3: Tá bom. [COOP+TDM]

A4: Possui uma raiz real, ãhn... Tá, a gente tem que dizer isso só não sei como... tal que... se y for igual a $0, x$ vai ser igual a zero, né, mas não sei dizer isso em uma palavra bonita. Tal que os valores somados de $x$ e y sejam zero? Não. [COOP+TDM]

A3: É, pode ser. É. [COOP+TDM]

A4: Não sei se "tal que" cabe nessa frase. [COOP+TDM]

A3: Tal que os valores de $x$ e y se anulam, dando zero. [COOP+TDM]

A4: Isso, se anulam, melhor do que somados. [COOP+TDM]

Fonte: Dados da pesquisa.

Após a exposição dos diálogos nos quadros apresentados, vemos que a partir das trocas de ideias e pensamentos entre $A 3, A 4$ e $A 5$, os mesmos conseguem formular algum conceito para o objeto em estudo. Durante o experimento de ensino observou-se constantes trocas entre os pares, os quais a cada novo desafio ou impasse eram colocados em questionamento para debate e reflexão coletiva. Entendemos que esse tipo de ação, segundo Piaget (1973), caracterizado por meio de equilíbrios parciais que vão sendo "atualizados" conforme nova ação pelo sujeito faz com que novos pensamentos sejam criados e ideias debatidas, caracterizando dessa forma um trabalho cooperativo.

Diante da apresentação dos diálogos e nossas análises frente ao referencial teórico desse artigo, primeiramente reconhecemos contribuições da cooperação em termos de alguma aprendizagem sobre as funções afim, visto que a forma de abordagem escolhida para ocorrer a apresentação e estudo do assunto valorizou a participação e ações dos estudantes, tanto no campo individual quanto coletivo no andamento da aula.

Figura 4 - Esquema entre cooperação e tecnologias móveis.

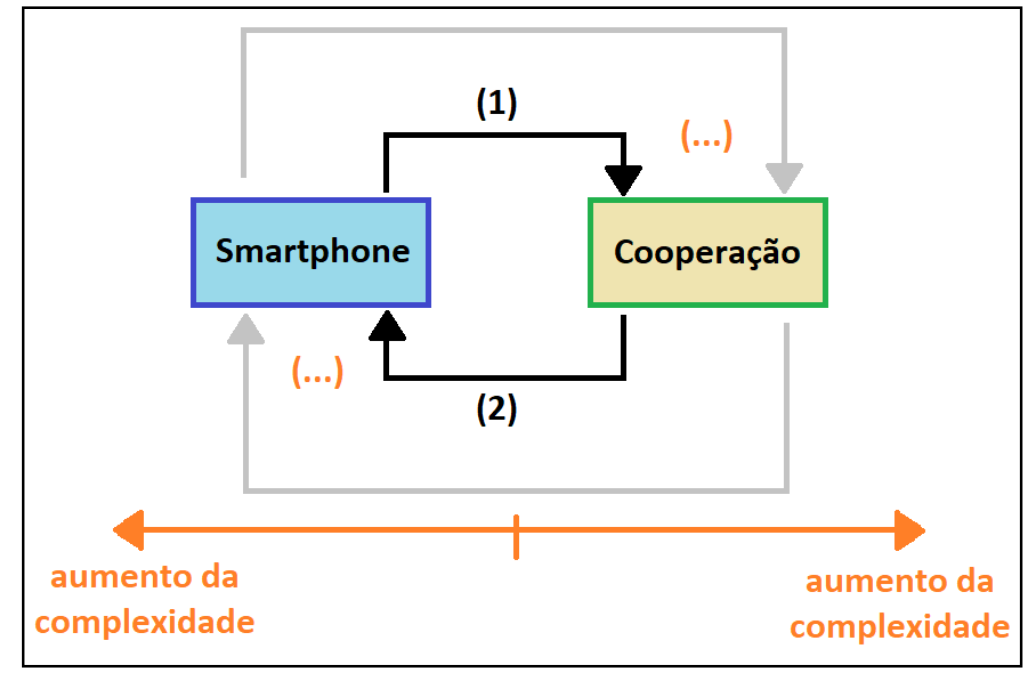

Fonte: Arquivo pessoal. 
Em um segundo momento, a partir das nossas observações nos diálogos estabelecidos entre os estudantes e também com a mediação da professora, concluímos que o uso das tecnologias móveis, em particular o smartphone, de alguma forma também contribuiu nos momentos de construção de argumentos sobre o conceito matemático em estudo. Usamos a figura 4 para ilustrar a ideia que foi apresentada nesse parágrafo.

Antes de encerrar nossa seção de análises cabe explanar uma reflexão a partir do esquema mostrado na figura 4. A partir do momento em que os smartphones passaram a ocupar espaço na vida pessoal dos estudantes, cabe notar que seja natural conceber que tais artefatos também possam ocupar os espaços educacionais. No que tange sobre o uso dos smartphones em atividades matemáticas, é notável perceber que ao convidar os estudantes para o debate e explanação das ideias a partir de uma perspectiva do trabalho coletivo, aqui subsidiado pela ideia de cooperação, a simbiose entre os movimentos (1) e (2) decorre do fato que devido ao aumento da complexidade dos assuntos e questões em debate, haja mais necessidade de ação por parte dos sujeitos envolvidos, seja inicialmente da forma individual, mas com viés para gradualmente migrar à ação em conjunto. Isso faz com que coexista, de forma implícita, um aumento e melhora na construção das hipóteses matemáticas em estudo e também haja uma exigência pessoal sobre um melhor uso das funcionalidades disponibilizadas pela tecnologia, tornando assim o smartphone um elemento co-participe do processo de ensino, por parte do professor, e da aprendizagem, por parte do estudante.

\section{Considerações finais}

A partir do nosso estudo que visou analisar a cooperação pudesse contribuir no processo de construção do conhecimento pelos sujeitos, refletimos que inserida em um contexto de atividade matemática em sala de aula foi oportunizado aos estudantes refletir e dialogar sobre a função afim. Além disso, o uso do smartphone, como recurso tecnológico, fez com que os estudantes manipulassem e observassem o comportamento do objeto matemático função afim para que ao final da sequência de atividades conseguissem elaborar algum conceito sobre esse conteúdo, e isso se alinha ao objetivo proposto e apresentado na introdução desse texto.

Nosso entendimento enquanto pesquisadores é o de que ao proporcionar um trabalho em grupo juntamente com a utilização da tecnologia móvel em sala de aula há oportunidade para que ocorram múltiplas aprendizagens, inclusive de matemática. Verificamos, a partir de nossas observações nos dados produzidos que essa condução de trabalho em sala de aula possibilitou aos estudantes por meio de debates entre os pares, que houvesse trocas de ideias e a partir disso, a construção de ideias matemáticas. Isso, em parte, responde a questão de pesquisa apresentada na introdução desse artigo, pois entendemos que a interações entre os sujeitos (cooperação) e dos sujeitos com a tecnologia oportunizaram uma confluência durante o debate e troca de ideias. Outros elementos, tais como abstrações a ações individuais, não estiveram no foco de nossa análise, portanto esses também podem ser elementos balizadores, junto com a cooperação na perspectiva da análise sobre a produção de conhecimento. Entendemos que o objetivo central da pesquisa, que tratava de observar, analisar e refletir sobre o trabalho coletivo dos estudantes no estudo de funções ao fazer uso das tecnologias móveis a partir de ações subsidiadas por meio de diálogo entre os pares tenha sido alcançado, pois nossa pesquisa não propôs um estudo aprofundado sobre as funções, tal como está previsto no Ensino Médio, porém fez uso de estratégias e recursos que pudessem 
ser mobilizados na perspectiva de exploração e construção de conceitos pelos estudantes já ao final do Ensino Fundamental.

Por fim, na forma de convite aos demais interessados da área da Educação Matemática, ansiamos que as nossas reflexões sobre a temática aqui exposta, provenientes da experiência aqui explanada, possam ser agregadas ao debate que envolve o uso de smartphones em espaços educacionais. A partir das leituras sobre os aportes teóricos explanados no presente artigo, os quais subsidiaram a construção das atividades e o percurso metodológico de trabalho realizado, o qual faz parte de uma pesquisa maior de mestrado em Ensino de Matemática, entendemos que oportunizar momentos de trabalho coletivo permeado por tecnologia habilita a sala de aula a se tornar um espaço com incomensurável riqueza de compartilhamento, estudo, empatia e promoção à aprendizagem. Notou-se, a partir da experiência e análise aqui mostrada, que ao estimular o diálogo entre os estudantes há um crescimento, tanto do grupo quanto do individual, e isso notoriamente se expressa por meio de aprendizagens.

\section{Referências}

BAIRRAL, M. A. As manipulações em tela compondo a dimensão corporificada da cognição matemática. Jornal Internacional de Estudos em Educação Matemática, São Paulo, v. 10, n. 2, p. 104-111, 2017.

BATISTA, S. C. F. M-learnmat: Modelo pedagógico para atividades de m-learning em matemática. 2011. Doutorado em Informática na educação. Programa de Pós-Graduação em Informática na Educação, Universidade Federal do Rio Grande do Sul, Porto Alegre, 2011.

BOGDAN, R.; BIKLEN, S. Investigação Qualitativa em Educação: uma introdução à teoria e aos métodos. Porto: Porto Editora, 1994.

BONA, A. Espaço de aprendizagem digital da matemática: 0 aprender a aprender por cooperação. 2012. Doutorado em Informática na Educação. Programa de Pós-Graduação em Informática na Educação, Universidade Federal do Rio Grande do Sul, Porto Alegre, 2012.

BRASIL. Base Nacional Comum Curricular. Brasília: MEC, 2018. Disponível em: http://basenacionalcomum.mec.gov.br/. Acesso em março de 2020.

CAMARGO, L. S.; BECKER, M. L. R. O percurso do conceito de cooperação na epistemologia genética. Educação \& Realidade, v. 37, n. 2, p. 527-549, 2012.

CORDEIRO, S. F. N. Tecnologias digitais móveis e cotidiano escolar: espaços/tempos de aprender. 2015. Doutorado em Educação. Faculdade de Educação. Universidade Federal da Bahia, Salvador, 2015.

FLICK, U. Introdução à pesquisa qualitativa; 3a Edição. Porto Alegre: Artmed, 2009.

FRANKLIN, T.; PENG, L. W. Mobile math: Math educators and students engage in mobile learning. Journal of computing in higher education, v. 20, n. 2, p. 69-80, 2008. 
GOMES, R. C. S; GHEDIN, E. O desenvolvimento cognitivo na visão de Jean Piaget e suas implicações na educação científica. In: GHEDIN, E. Teorias Psicopedagógicas do ensino-aprendizagem (pp. 214232). Boa Vista: UERR Editora, 2012.

HIGUCHI, A. A. S. Tecnologias móveis na educação. Dissertação de Mestrado em Educação, Arte e História da Cultura. Universidade Presbiteriana Mackenzie. São Paulo. 2011.

MARTINS, E R; GERALDES, W. B.; AFONSECA, U. R.; GOUVEIA, L. M. B. Tecnologias Móveis em Contexto Educativo: uma Revisão Sistemática da Literatura. RENOTE: Novas Tecnologias na Educação, Porto Alegre, v. 16, n. 1, julho, 2018.

MARQUES, T. B. I. Professor ou pesquisador? In: BECKER, F.; MARQUES, T. B. I. (orgs). Ser professor é ser pesquisador. Porto Alegre: Mediação, 2007.

MOURA, A.; CARVALHO, A. A. Enquadramento teórico para a integração de tecnologias móveis em contexto educativo. In: I ENCONTRO INTERNACIONAL TIC E EDUCAÇÃO: INOVAÇÃO CURRICULAR COM TIC. 2010, Lisboa, atas. Universidade de Lisboa: Instituto de educação, 2010, p. 1001-1006.

OLIVEIRA, B. As contribuições psicogenéticas para a convivência democrática: da escola para a vida. Revista Eletrônica de Psicologia e Epistemologia Genéticas. v. 11, n. 2, p. 145-163, 2019.

PIAGET, J. Estudos sociológicos. 1a Edição. Rio de Janeiro: Forense, 1973.

PINTO, S. R. Ensino de funções quadráticas com o GeoGebra Graphing Calculator na escola básica: um olhar para a cooperação entre os estudantes. Trabalho de conclusão de curso. Universidade Federal do Rio Grande do Sul, Porto Alegre, 2018.

SONEGO, A. H. S. Arqped-mobile: Uma arquitetura pedagógica com foco na aprendizagem móvel. 2019. Doutorado em Educação. Programa de Pós-Graduação da Faculdade de Educação, Universidade Federal do Rio Grande do Sul, Porto Alegre, 2019.

STORMOWSKI, V. Vale a pena utilizar tecnologias digitais na educação? In: SILVA, R. S. (orgs); Diálogos e reflexões sobre tecnologias digitais na educação. São Paulo: Editora Livraria da Física, 2018.

TREVISO, V.C. As relações sociais para Jean Piaget: implicações para a educação escolar. 2013. Mestrado em Educação Escolar. Programa de Pós-Graduação em Educação Escolar da Faculdade de Ciências e Letras, Universidade Estadual Paulista, São Paulo, 2013.

WHITE, T.; MARTIN, L. Mathematics and Mobile Learning. TECHTRENDS. v. 58, p.64-70, 2014. 